\title{
Imagem, Paisagem e Turismo: a construção do olhar romântico
}

\author{
Susana Gastal* \\ Universidade de Caxias do Sul
}

\begin{abstract}
Resumo: A presente análise, de viés semiótico, parte da marca pós-moderna de ênfase no visual. Resgatam-se construções históricas em torno da Imageme da Paisagem, para aproximá-las do Turismo. A construção de imagem da Paisagem romântica, como sistematizada naquele período, priorizou o pitoresco, ou seja, um olhar sobre a natureza que a via como um jardim harmonioso e acolhedor. O presente artigo, filiado a teoria do texto conforme Barthes, tem por objetivo associar tal visualidade ao Turismo, considerando ser ele um fenômeno econômico e social que se estruturava e expandia no mesmo período. A estética de pitoresco marcará a visualidade dos primeiros destinos turísticos de montanha e litoral, sendo reproduzida nos guias de turismo e se fazendo presente ao longo do século XX nas imagens turísticas.
\end{abstract}

Palavras-chave: turismo,imagem, paisagem, romantismo, pitoresco.

\section{Image, Landescape and Tourism: the construction of romantic look}

Abstract: This review discusses the notion of landscape as it emerges thematically in the Romantic painting. The romantic construction of image as it is systematic in the landscape in that period prioritized the picturesque, ie, the nature as a harmonic and welcoming garden. This article is affiliated to Barthes text theory and it aims to link this landscape aesthetics to tourism, considering it as social and economic phenomenon that was structured and expanded in the same period. The aesthetics of the picturesque will mark not only the first destinations of mountain and coastal areas as will be present throughout the twentieth century tourism visually.

Keywords: tourism, image, landscape, romantic, picturesque.

\section{Introdução}

É lugar comum dizer que vivemos num mundo de imagens, mas, a se considerar tal afirmação como verdadeira, é curioso que a atenção dada ao seu estudo, fora das áreas especializadas, como as artes visuais, ainda seja pequena. No turismo não tem sido muito diferente, embora autores como Castrogiovanni (2009), Serrano (1997) e Luchiari (s.d) analisem o tema, não por acaso de um ponto de vista da geografia e do território e, ato contínuo, associado à paisagem.Levando-se em conta que uma das expressões mais comuns no jargão turístico é o sightseeing, que designa o passeio local para 'olhar' o lugar visitado, mas que o Google tradutor apresenta simplesmente como 'turismo', este exemplo singelo mostra que as construções de sentido associadas ao olhar turístico vão muito além da questão da paisagem e que uma reflexão sobre suas aproximações sig-

* Professor, pesquisador e orientador no Programa de Pós-Graduação em Turismo - Mestrado, da Universidade de Caxias do Sul. E-mail: susanagastal@gmail.com 
nifica, em simultâneo, uma maior compreensão da atividade que mobiliza milhões de pessoas, ao redor do planeta.

No que aqui pretendo abordar - a construção do olhar do turista como um olhar romântico levarei em consideração a paisagem, sim, mas em desdobramento a uma questão anterior, qual seja, a imagem. Enquanto a paisagem, se associada ao território, se coloca no momento da empirização da viagem (Cisne, 2010), a imagem se faz presente ao olhar do turista antes mesmo de seu deslocamento, pois quando tal acontece, "as pessoas já terão entrado em contato com o mesmo visualmente, através de fotos em jornais, folhetos, cenas de filmes, páginas na Internet ou mesmo pelos velhos e queridos cartões postais" (Gastal, 2005:12-13). O que pretendo arrazoar é que o olhar do turista é resultado de uma construção histórica que se dá em simultâneo com o estabelecimento da organização social e de mercado do que chamamos de Turismo, no século XIX. Nos períodos subsequentes, mesmo que a atividade tenha se ampliado na sua presença na sociedade e que apresente novas performances, observa-se que a estética a condicionar o jeito de olhar e o que é visto, se mantem a mesma.

A construção metodológica para a análise aqui proposta, de base semiótica, parte de Barthes (1987b) quando ele afirma que mesmo imagens podem ser lidas como textos. Semioticamente, o texto é aberto e plural, um território onde interagem outros textos: histórico, social, econômico, linguístico e mesmo o psicológico. Como afirma Jameson (1992:305), "a extrapolação da noção de 'discurso' ou 'escritura' para objetos que antes se acreditava serem 'realidade' ou objetos do "mundo real" amplia as possibilidades de análise. Trabalha-se não com o real, mas com suas re(a)presentação, o que carrega em si a contingência de mediação, contrária ao termo realidade, que suporia a presença imediata, não reflexiva da construção e recepção estética. Portanto, imagem, paisagem e turismo serão os textos em questão, percorridos na sua representação e intertextualidade.

No artigo, inicio com o resgate da construção do conceito de imagem, utilizando para tal a teorização das Artes Visuais, nas quais o conceito teria nascido como uma temática específica na pintura, sendo, pois, elas, as artes, pioneiras não só na criação da expressão visual, mas também na sua teorização. A seguir, busco uma reflexão sobre a paisagem e sua apropriação no Turismo, em muito associada à ideia de pitoresco, construída pelos primeiros guias de turismo, que entram em circulação no século XIX.

\section{Imagem}

As tecnologias da imagem desdobram-na em diferentes telas - a fotográfica, a cinematográfica, a do computador... - impondo sua presença e o recuo das formas de comunicação marcadas pela escrita. A imagem fotográfica, estática, é colocada em movimento pelo cinema, logo acompanhada de outras construções temporais dramatizada, permitidas pela forma de montagem de cenas de maneira não cronológica - embaralha-se o antes e o depois -, nos replay ou no slowmotion, que desdobra a cena rápida em infindáveis segundos. Condicionando o olhar e transpondo a tela, a dimensão estética aportará os cotidianos na forma de design, arquitetura, decoração ou moda, para alcançar o corpo e a aparência física das pessoas, os materiais publicitários, os produtos turísticos e sua publicidade.

O estético, portanto, se coloca como uma das principais marcas do momento Pós-moderno, pois igualariatodos produtos colocados no mercado, com destaque para os produtos culturais - aí incluído o Turismo - com exigências para além das pertinentes ao seu uso ou desfrute, pois a eles deve ser agregada uma visualidade qualificada ao gosto da maioria.Entretanto, em que pese ao avanço das possibilidades disponibilizadas pelos avanços dos efeitos de dramatização das imagens, a partir da tecnologia, é possível afirmar que a estética a elas subjacente, em geral, é bem mais conservadora e reportaria ao Romantismo. Conforme Read (1989:399), o Romantismo significou:

"Profunda revolução no espírito humano que ganhou ímpeto no séc. XVIII e estava em pleno florescimento no séc. XIX. [...] Os elementos mais importantes do R. eram: receptividade para a natureza (prefigurada pelo pitoresco); uma ênfase na sensibilidade subjectiva, na emoção e na imaginação, por oposição à razão; um interesse pelo passado, o misterioso e o exótico."

Hauser (1969), por sua vez, afirma que o Romantismo tornou-se um movimento generalizado por toda Europa, que abarcaria nação após nação e criaria uma linguagem literária e visual que se universalizaria, sendo "compreendida tanto na Rússia e na Polônia como na Inglaterra e França [...]. De fato, não há produto da arte moderna, não há impulso emocional, não há impressão ou disposição de ânimo do homem moderno, que não deva a sua sutileza e sua variedade a sensibilidade nervosa originada no 
Romantismo". O mesmo teórico apresenta outras marcas do Romantismo, além das já propostas por Read, como a utopia, que encontraria inspiração em ideais que o ideário do movimento acreditava já realizados no passado; a fuga, também está ligada ao passadismo, pois a experiência romântica da História expressaria um medo mórbido do presente e uma intenção de fuga ao passado; o dinamismo, se considerado que a imagem de mundo, anterior a ele, seria estática e ahistórica. Ainda sobre o passado, subjacente à utopia e à fuga, para Hauser(1969) nenhuma outra geração teria tido de maneira tão aguda o sentimento de ser herdeira e descendente de períodos anteriores, vendo no passado uma cultura perdida, que deveria ser despertada para uma nova vida.

Tal passadismo estará presente, por exemplo, nas viagens de Goethe (1749-1832), em especial à Itália, que depois são transformadas em livros; ele seráum dos criadores do movimento literário alemão sturmunddrang [tempestade e ímpeto], que alimentou-se da estética do sublime. A valorização da natureza estará presente nas pinturas de John Constable(1776-1837) e de Joseph Turner (1775-1851), "que mostram uma nova consciência da paisagem" (Read, 1989:399), embora com ênfases diferentes, conforme pode ser observado nas figuras 1 e 2 .

No contexto romântico, o termo pitoresco entra em voga no final do século XVIII, evocando

“[...] imperfeições e assimetrias em cenas repletas de detalhes curiosos e característicos que procuram remeter a uma natureza acolhedora e generosa. Valoriza-se aí a irregularidade (sempre agradável) da natureza e a interpretação poética de uma atmosfera particular. [...] O pitoresco designa, nesse contexto, tanto o objeto natural quanto a sua representação num quadro. A expressão artística exemplar do pitoresco é a paisagem dos jardins ingleses. Aliás, o pitoresco, segundo Giulio Carlo Argan, 'expressa-se na jardinagem', arte de educar a natureza, melhorando-a, mas sem tirar-lhe a espontaneidade. O sublime apontando para o trágico, o infinito e o universal; o pitoresco enfatizando o característico, o mutável e o relativo". (Itau Cultural, s.d., s.p.).

O pitoresco, na sua origem semântica no pintoresco do italiano e do espanhol, significaria o que se pode pintar. Já o sublime teria uma construção de sentido um pouco diferenciada:

"O termo sublime, do latim sublimis, entra em uso no século XVIII indicando uma nova cate-
Figura 1: Constable.Malvern Hall.1809. Acervo Tate Gallery, Londres.

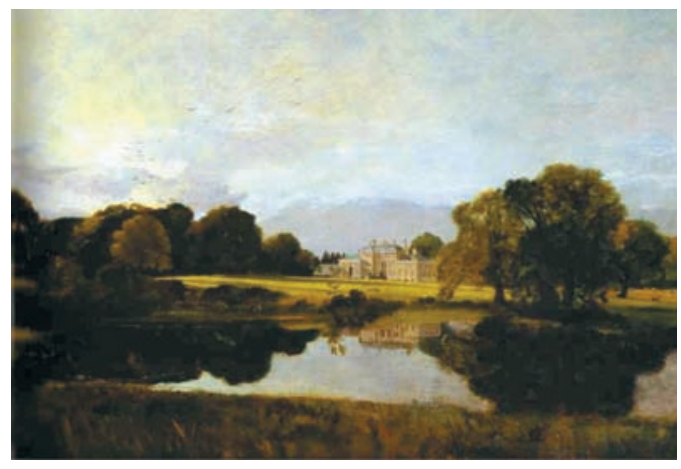

Figura 2: Turner. Calais Pier.1803

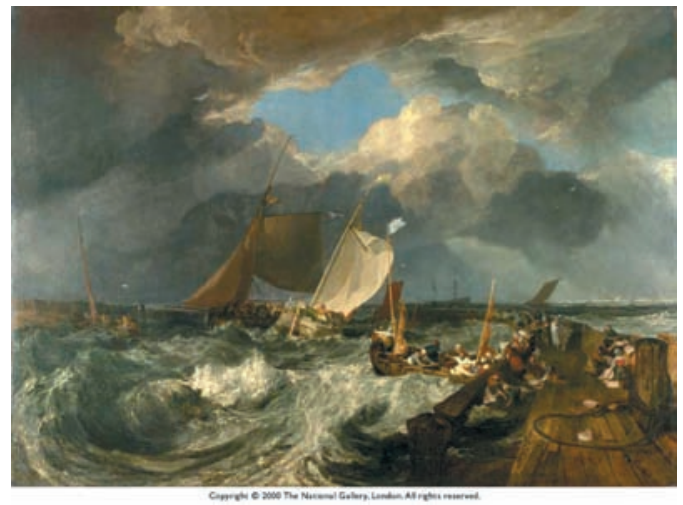

goria estética, distinta do belo e do pitoresco, e remete a uma gama de reações estéticas com a sensibilidade voltada para os aspectos extraordinários e grandiosos da natureza. Para o sublime, a natureza é ambiente hostil e misterioso que desenvolve no indivíduo um sentido de solidão. [...] Nas artes visuais, o culto do sublime conhece expressões muito variadas, embora seja possível localizar nele traços dominantes: o caráter visionário do sublime é representado, de modo geral, por cores empalidecidas e sem brilho, por traços marcados e gestos excessivos. $\mathrm{O}$ gosto pelas paisagens selvagens e inóspitas do pintor napolitano Salvator Rosa, de ampla aceitação na Inglaterra, exerce grande influência no desenvolvimento do sublime. Penhascos escarpados e árvores retorcidas criam uma ambiência de desolação que contrasta com a grandeza clássica do paisagismo de Nicolas Poussin. [...] Mas os dois artistas que melhor sintetizam o sublime na pintura são Joseph Mallord William Turner e Caspar David Friedrich. Nas telas de Turner, a natureza se mostra como potência 
desvastadora, como fogo ou como força marítima" (Itau Cultural, s.d, s.p.).

Será em período concomitante, que as imagens fotográficas começarão a ganhar popularidade, em trabalhos como os de Timothy O'Sullivan, que retrata suas viagens, como na figura 3.

Figura 3: O’Sullivan.Shoshone Falls, Idaho. 1868

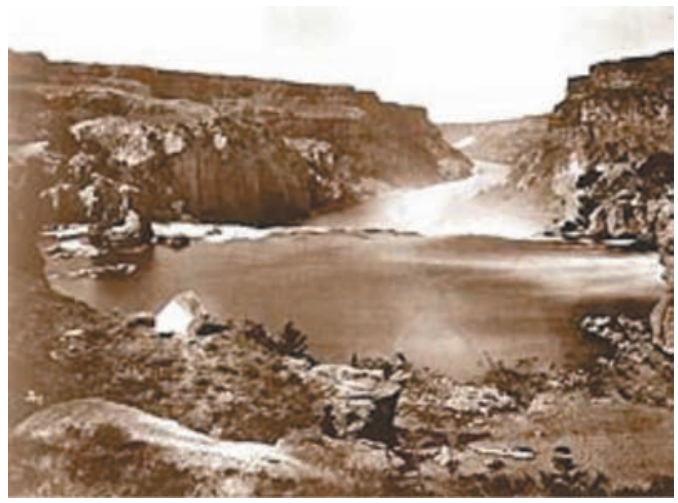

Em termos de construção visual, outra foto, esta de Henry Taunt, aproxima ainda mais a estética do pitoresco, na sua reprodução de uma cena de tranquilidade:

Figura 4: Taunt. Maidenhead Railway Bridge.1883. Acervo: Oxfordshire County Council Photographic Archive.

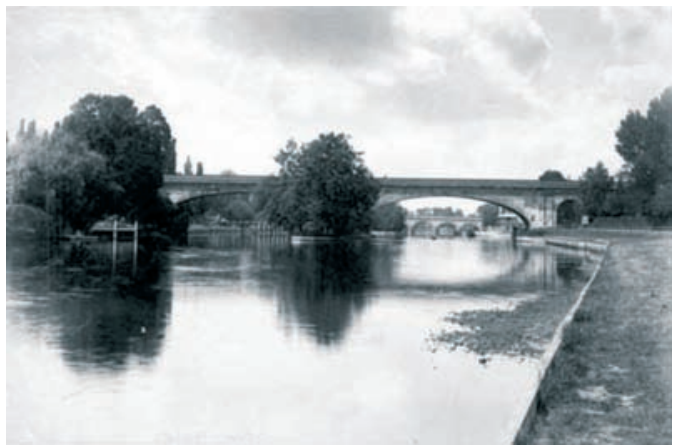

Será esse olhar romântico, associado ao pitoresco e não ao sublime, que irá embalar esteticamente outro fenômeno social que começa a se manifestar neste mesmo século: o Turismo. Antes de aprofundar esta outra aproximação, se faz necessário resgatar também o percurso da paisagem, para então aproximá-la, como imagem privilegiada, ao turismo.

\section{Paisagem}

No senso comum, a paisagem esteve por muito tempo associada à natureza e, como tal, condicionada às relações que determinado grupo social mantivesse com ela. As culturas agrícolas tradicionais, mais antigas, cultivavam uma relação direta e literal com a natureza, sendo os cotidianos condicionados pela luz do sol e pelas estações do ano. $\mathrm{O}$ avanço da máquina e depois da indústria, com a Modernidade, ocasionaram um maior distanciamento da natureza, inclusive, nos espaços rurais. Sob a perspectiva industrial, os bens naturais transformam-se em matéria-prima para produção, atitude contestada apenas na década de $1960^{1}$, quando discursos acadêmicos e sociais passaram a salientar finitude de tais recursos. O discurso pós anos 1960 salientava o conceito ecossistema, cuja concepção alterava a visão homocêntrica moderna, para uma visão na qual as pessoas seriam partícipes de um grandesistema, interligado e interdependente. Vigorava, ainda, um conceito de natureza como designativo daquelas partes do mundo, não alteradas pela mão humana.

Fredric Jameson (1996:13) é drástico ao considerar a possibilidade de algum espaço ainda não alterado pelo humano, o que o leva a afirmar que o "pós-modernismo é o que se tem quando o processo de modernização está completo e a natureza se foi para sempre”. Ele não chega a dizer, mas é possível deduzir que, na noção de ecossistema apregoada pelos ecologistas e hoje generalizada pela sociedade, talvez, o que desapareça seja a própria natureza, relegada a mais uma das grandes narrativas questionadas pelos pós-modernos. Hoje, na forma de ecoturismo, de jardins botânicos e zoológicos, de produtos organicamente corretos, de objeto de estudos acadêmicos, de paisagismos ou mesmo na forma de paisagem, a natureza é mais um produto culturalizado e dilatado como mercadoria.

Nessa contingência, perdida a natureza, o conceito de paisagem, ao ganhar a forma de produto, terá no turismo e na sua publicidade, agenciadores privilegiados - mas, a destacar, não exclusivos -, e também conquistará espaço teórico, no qual será a própria teorização que constituirá o objeto de estudo, ou seja, a construção do conceito paisagem. Assim, começam a aparecer trabalhos acadêmicos a discuti-la e sua abrangência se expande para abarcar, por exemplo, a noção de paisagem cultural.

A presença histórica da concepção de paisagem reportaria a Modernidade, inaugurada no Renascimento. Antes, o indivíduo e natureza seriam um todo. Nela inseridas, as pessoas não 
poderiam lançar o olhar sobre, caracterizando o distanciamento que permitisse vê-la como um objeto, ou seja, um outro separado de si. Nesse período, a paisagem não seria, ainda, apresentada nas expressões plásticas como cena, pois todos os elementos presentes no quadro são tratados separadamente, como elementos de fundo. É indiferente se os elementos de fundo são flores, folhagens, animais, ou outro grafismo qualquer. "Flores, folhas e árvores coisas que podem ser pensadas isoladamente. Uma montanha é uma 'coisa', quando a sua forma é suficientemente egrégia para a distinguir do conjunto. As primeiras paisagens são constituídas por estes elementos individuais" (Clark, s/d:164). As 'coisas' são tratadas de forma naturalista, e as pessoas, se presentes, estão integradas a elas.

Antes, durante a Idade Média, haveria dois tipos de olhar sobre a natureza: o religioso, no qual a natureza, se fonte de prazer sensorial, seria tambémfonte de pecado e engano d'alma; e o do camponês, enquanto quem trabalha a e na natureza, e que a vê associada ao esforço e ao trabalho. $\mathrm{Ou}$, pior, a natureza poderia ser origem de males tenebrosos: do mar viriam os piratas, as florestas seriam habitadas por seres humanos e não humanos como a bruxa má e o lobo mau, dentre outros, todos hostis. Mesmo manifestações da natureza, como as tempestades, poderiam serfonte de destruição. A passagem dessa natureza hostil, para a ideia de natureza como paraíso, dar-se-ia no bojo das ideias de S. Francisco de Assis (1181 - 1226), que pregara a harmonia entre as pessoas, as plantas e os animais. Clark (s.d.) analisa a importância da luz, nesta passagem: Se Deus é luz, se a luz está em todas as coisas, Deus estaria em todas as coisas, unindo-as. A natureza, iluminada, passa a simbolizar a perfeição divina.

$\mathrm{Na}$ cidade medieval, murada, o que estivesse logo além dos muros é chamado de campo; floresta será o que ficar além do campo. O jardim demarcará o que estiver entre os muros; o jardim cercado é a natureza sob controle, domada, que pode ser vivenciada para o prazer e a felicidade, aí presente a ideia de harmonia. É neste cenário que o paraíso será simbolicamente colocado, tornando-se grande pecado o querer atravessar os muros para buscar o que estaraia além deles.

Ainda nesse momento medieval, o que também está fora do olhar e do universo sensorial do artista e das demais pessoas, são as montanhas, desconhecido a ser apreendido. O imaginário coletivo coloca, também ali, muitos perigos. Numa época de trabalho e pecado, o prazer gratuito do escalar montanhas e, portanto, conhecê- -las, não existia para o homem medieval, muito menos para as mulheres. Distantes, enormes, representá-las de maneira convincente é problema que se coloca aos artistas. O pintor tenta resolver a questão utilizando pedras como inspiração do olhar. Elas são levadas para o ateliê e, ali, cuidadosamente copiadas. O recurso funciona razoavelmente para a representação dos rochedos mas, como a montanha é muito mais do que uma pedra ampliada ou um rochedo, o resultado aparece como artificial. Só Friedrich (1774-1840), no romantismo alemão, solucionará tal questão pictórica.

O Renascimento trará a paisagem ainda funcionando como fundo, o primeiro plano ocupado pela figura. Houve, segundo Clark (s/d), de maneira clara, uma alteração no processo de incorporação e dominação da natureza. Um bom exemplo é a Monalisa, pintada por Leonardo Da Vinci, em 1506. A Paisagem ao fundo da figura não registra sinal de vida humana e contrasta com a figura bastante moderna da protagonista. $\mathrm{O}$ tipo de composição ao fundo - o caminho, o riacho - tem um rebatimento no rosto e no pano da roupa, criando uma continuidade com a figura.

\section{Figura 5: Da Vinci.Monalisa. 1506. Acervo Museu do Louvre}
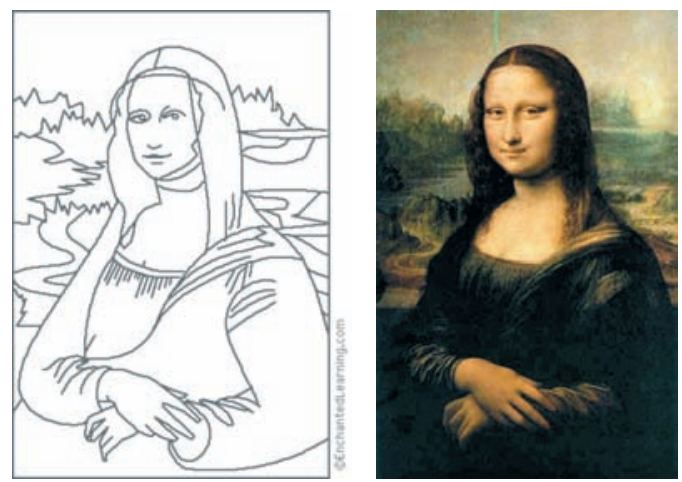

A sensação da paisagem como cena só se dará com o desenvolvimento da perspectiva, que demarcará mais formalmente, o Renascimento. A cena trás uma construção espacial em profundidade, na sucessão de planos. De padrão decorativo utilizado para completar a composição, a natureza passa a cenário, onde são representados eventos ou fatos. A perspectiva construída a partir de um ponto de fuga é uma abstração. Nela, o observador prescinde da experiência sensória: se todas as informações estão disponíveis, é possível criar um ambiente sem nunca tê-lo visto. Cria-se um antagonismo: o máximo 
de representação fiel da realidade, sem o consequente rebatimento empírico.

A história das imagens nos mostra que a perspectiva, "uma realização vital da Renascença que moldou as maneiras de ver por quatro séculos" (Harvey, 1992:222), já homogeneizara o espaço a ela submetido. Materialização visual do pensamento iluminista, que buscava uma sociedade laica mais racional e menos subordinada à intuição, baseava-se na ordenação racional do espaço e do tempo como requisito à construção de uma sociedade mais avançada, que garantisse as liberdades individuais e o bem-estar humano. Nos espaços nascidos da perspectiva, há um "ponto de vista elevado e distante, completamente fora do alcance plástico ou sensorial. Ele gera o sentimento de espaço 'friamente geométrico' e 'sistemático', mas que produz 'uma sensação de harmonia com a lei natural, acentuando assim a responsabilidade moral do homem no âmbito do universo geometricamente organizado de Deus" (Idem, p.222). A perspectiva, entretanto, deixará ainda uma questão irresolvida: como representar o céu e as nuvens, ambos não decifráveis matematicamente? Esta questão só será solucionada, pictoricamente, com o advento da fotografia, permitindo que fotos de nuvens fossem utilizadas pelos pintores, como modelo para representação.

A noção e o termo paisagem, mais propriamente, só teriam surgido no século XVIII, para designar o gênero de pintura que retratava o campo e os objetos que ali se encontram. Será apenas em meados do século XIX, com o Romantismo, que a paisagem ganhará imagética própria e passará a ser tema dominante na pintura, ou seja, de complemento à figura, a natureza passa a motivo central do quadro. A paisagem ganha espaço não apenas no âmbito da tela, mas na concepção de natureza, da sociedade. No século XVIII, os grandes artistas haviam sistematizado as regras de composição que, no século seguinte, orientarão as regras de composição na pintura. Nesse caminho, a temática "vai das coisas às impressões" (Clark, s/d:164), ou seja, evolui da colocação de elementos naturais isolados na composição, para constituir-se em um todo em que a luz e a iluminação terão papel fundamental.

A pintura de paisagens terá seu período de apogeu para, depois, tornar-se um estilo que acaba perdendo sua exuberância, não sem antes passar por exacerbações e degeneração, para cair no caricato. A situação é ironizada por Gustave Courbet, na tela Atelier (1855), onde está o artista e sua modelo, ela, nua, e ele pintando uma paisagem (v. figura 6). Chama atenção o fato de a cena acontecer dentro do ateliê do artista, pois, na época, se considera que um nu ou uma natureza morta poderiam ser pintados entre quatro paredes, mas pintar a natureza exigiria que o pintor fosse até ela.

\section{Figura 6: Courbet, G. Estúdio do Pintor. 1855. Acervo Museu D’Orsay, Paris.}

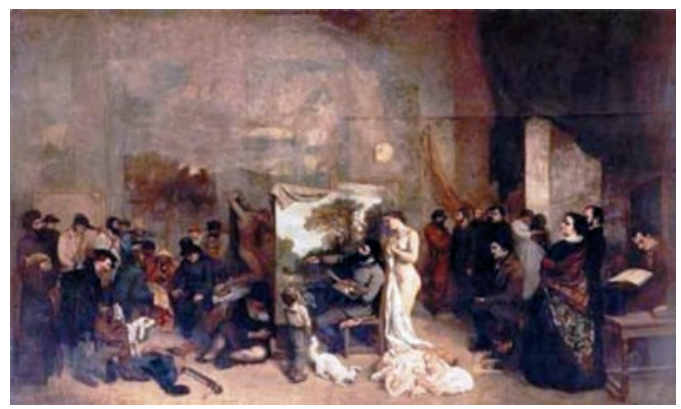

A ordenação visual iluminista, associada à perspectiva, será desafiada pela tecnologias do século XIX, a partir do momento em que a imagem é desconstruída na paisagem vista pela janela do trem ou registrada pela máquina fotográfica. Muda o olhar, menos orientado pela racionalização implícita na perspectiva: a paisagem que passa célere pela janela, fala antes ao sensorial do que ao intelectual do observador. De certa forma, nesse momento se inicia o processo de desmaterializa da imagem-paisagem. Os impressionistas registraram essa mudança em suas telas, com suas pinceladas fluídas, a figura liberando-se da prisão da linha. A pesquisa modernista posterior manterá vertentes de construção visual atreladas à experiência sensorial, em especial em termos de cor - como no impressionismo e noutros abstracionismos - e outras vertentes racionalistas, como o cubismo e o concretismo, trabalhando em especial a partir da linha.

A percepção do espaço é social e socialmente construída, portanto, não é surpresa que ela sofra profunda modificação ao longo do tempo, quer nas relações com o território próximo, quer na relação com espaços completamente novos, que podem nascer de intervenções concretas ou simbólicas: viver o espaço é uma construção de sentido que condiciona a sensibilidade, mas que também é condicionada por ela. Constitui-se, portanto, como imagens e imaginários. Ver o espaço como fruto de uma construção social de imagens e imaginários significa admitir que os espaços diferem de cultura para cultura, ou seja, que se esteja lidando no campo do significante e não apenas do significado. O espaço, assim, é 
passível de leitura semiótica em suas práticas, discursos, jogos textuais e superfícies: o espaço é um texto. Múltiplo, objeto de construção de sentido e de leitura, o espaço sob essa compreensão estimula o olhar, exigindo um espectador ativo. O espaço se dá aos nossos sentidos, principalmente, pelo olhar, embora os demais sentidos contribuam para as trocas que se efetuam nele e com ele. Se o olhar é privilegiado, o espaço será, em princípio, imagem, ou, como prefere Jameson (1996), narrativa visual.

A relação com o espaço tem sido condicionada e alterada pela tecnologia, não apenas aquela que permite criar e reproduzir imagens, mas também por aquela que possibilita diferentes formas e velocidades nos deslocamentos. Deslocar-se supõe adequar o olhar à velocidade. Nossos ancestrais nômades, que se deslocavam a pé ou, na melhor das hipóteses, conduzidos por animais, podiam desfrutar a paisagem dos percursos nos seus detalhes, em íntima integração com ela. A roda e, depois, o motor, altera a velocidade e o modo de olhar: quem se desloca não está mais na paisagem, mas a observa com distanciamento. $\mathrm{O}$ conceito de paisagem acompanha estas mudanças. Para o geógrafo Antonio Carlos Castrogiovanni, hoje teríamos a paisagem:

"[...] entendida como um conceito que traduz o aspecto global - o visível e o invisível/ sentido, mas não visto - de uma área. Ela envolve os elementos físicos/naturais, suas interações, assim como todas as intervenções e articulações provocadas pela ação humana. Portanto, também fazem parte da paisagem os elementos históricos e culturais que sinalizam o processo organizacional dos diversos grupos sociais, construídos ao longo do tempo. A paisagem é resultado do acúmulo de ações temporais" (Castrogiovanni, 2001, p.132).

Nesse conceito para paisagem, mais contemporâneo, a ideia de natureza não só perde a centralidade, como praticamente desaparece. Outros fatores passam a compor as narrativas visuais na pós-modernidade, confirmando o proposto por Jameson (1996), que vê a Natureza - nesses termos com maiúscula - para sempre desaparecida. A migração da noção e sua expansão para além da geografia permitem outras apropriações, como, por exemplo, o conceito paisagem cultural, que "originário da Convenção da Unesco de 1972, foi concebido para responder à crescente complexidade da sociedade contemporânea e a velocidade cada vez maior dos processos sociais e econômicos" (Almeida, 2007:s.p) ${ }^{2}$.

\section{Imagem, paisagem e turismo}

Castrogiovanni (2001, p.132) olha a partir da geografia do Turismo explica que "a oferta turística é o resultado de todas aquelas atividades produtivas que servem à formação dos bens e serviços necessários à satisfação da necessidade turística e que se exprimem no consumo turístico", colocando-se, portanto, entre estes bens, a paisagem. Castrogiovanni busca outros autores, para melhor entender o que possa se colocar como paisagem turística:

"Segundo Rodrigues (1997, p.72) 'a paisagem é um notável recurso turístico desvelando alguns objetos e camuflando outros por meio da posição do observador, quando pretende encantar e seduzir`. Já para Pierre George (apud Lozato-Giotard, 1990:38), paisagem é 'a porção do espaço analisada virtualmente'. Ainda para Pitte (1990:38), citado na mesma obra, 'a paisagem é uma realidade cultural, pois não é somente trabalho humano, mas também objeto de observações, inclusive consumo. A cultura desempenha um papel de filtro variável de um para outro indivíduo e de um para outro grupo social. Este fenômeno de movimentos é fundamental nas paisagens turísticas que são avidamente contempladas mas também profundamente ordenados para melhor serem observadas" (Castrogiovanni, 2001, p. 132).

Se, conceitualmente, a paisagem turística é assim colocada, ou seja, como dependente do olhar do espectador, que seleciona e hierarquiza o que vê, é necessário retomar a teorização das artes visuais para decodificar suas marcas visuais, utilizando-se para tal as noções de sublime e pitoresco, já descritas, que demarcaram a paisagem no seu auge enquanto estilo de pintura, período concomitante, nos séculos XVIII e XIX, a constituição dos primeiros destinos turísticos. Considere-se, para tal, que com certa frequência é apresentado que o turismo moderno se constituiu na busca de locais pitorescos junto à natureza, ou seja, de destinos de sol, mar e montanha, sem que se coloque maior atenção sobre como esses espaços são apresentados ou como se realizou a sua construção de sentido. Barthes procurou realizar uma desconstrução que levasse a essa compreensão, como apresentado adiante.

Utilizando um dicionário, para reportar ao senso comum, o mesmo registra que pitoresco seria o divertido, o recreativo, o gracioso (Ferreira, s/d:1105). Para além do uso cotidiano que 
o consagrou nesta concepção, o pitorescoé compreendido nas artes de forma mais específica, que, como já colocado, na sua comparação com o sublime, apresenta-se como uma estética que procura remeter a uma natureza acolhedora e generosa, à natureza educada, vista como jardim.Quando adjetiva o termo paisagem - paisagem pitoresca - mostra como a estética da pintura foi incorporada e condicionou o olhar, e como que a expressão passou a ser sinônima de belo e de natural: em outras palavras, não haveria paisagem feia (Deprest, 1997).

Remetendo às viagens, Boyer (2003:39) afirma que o Turismo teria sido inventado: "O turismo nem sempre existiu. $\mathrm{O}$ fenômeno designado, na época romântica, por uma nova palavra, por um neologismo, decorre de The Tour [...]". A invenção se daria no contexto romântico, porque, segundo o teórico, teriam surgido,

“[...] então, o amor pelo campo, que se tornara lúdico, a transformação das práticas populares de uso das águas no termalismo mundano das estações termais que se estendeu até os balneários oceânicos, o desejo de ir aos limites e as invenções das Geleiras, do Mont Blanc e do alpinismo e, enfim, a longa temporada de inverno no sul da França. O Romantismo prolongou estas invenções com sua descoberta do exotismo no tempo e no espaço" (Boyer, 2003, p.19).

Se a passagem do século XVII para o XVIII fora demarcada pelo The Tour ou Grand Tour (Idem, p.22), na passagem para o século XIX aconteceria o que Boyer denomina de revolução turística. A demarcar o novo período, a presença de Cook que, em 1841, teria organizado aquelas que são consideradas como as primeiras excursões na Inglaterra; em 1857 há o nascimento do British Alpine Club, logo copiado em outros países europeus, e em 1879 surgiria o Ciclist Touring Club. Em 1890, houve a fundação do Touring Club de France, seguindo o exemplo inglês, e em 1895, a criação dos Amigos da Natureza, em Viena (Idem, p.26). Presença importante, ainda, a figura de Jean-Jacques Rousseau que, já em 1776, "andava a pé; o Romantismo o consagrou como 'o primeiro turista" (Idem, p.24). A exemplo de Rousseau, outros escritores românticos realizaram viagens a Suíça, a Veneza, ao Reno,e as relataram em seus escritos. Se até aqui temos um campo que se organiza em torno TheTour, construindo o conceito de viagemturística, a reprodução desse imaginário teria a fundamental participação dos guias de viagem. Em 1836 foi editado o primeiro, o Handbook Murray; e "em 1841, Ad. Joanne publicou o Itinéraire de laSuisse e 1843, Baedeker começou a edição de seus Guias" (idem, p.25).

"As três grandes coleções de Guias (inglesa, francesa, germânica) codificaram, na época romântica, a videnda dos turistas (primeiro a Itália, a Suiça, Paris...), divulgaram-nas até os nossos dias e por sua constante repetições (eles se copiam), fixaram o olhar do turista. As massas de hoje, assim guiadas, ainda têm as emoções dos Românticos [...]. Os locais do turismo de massa são vistos, fotografados com 'lentes cor de rosa'” (Boyer 2003, p.25).

O imaginário com lentes cor de rosa, gestado dentro de um ideário romântico, nasce em uma época em que "somente as pessoas de alta renda - ou quase - eram turistas. Todas as grandes estações termais, balneárias, de alpinismo (Chamonix, Zermatt), de inverno mediterrâneo, os grandes lugares que se deve conhecer - videnda ou sight-seeing- tem uma data de nascimento e muitas vezes bicentenários" (Idem, p.25). Os guias - o Murray inglês, o Baedeker alemão e o Joanne francês - se encarregariam de alimentar a reputação destes lugares.

A estética, então construída, irá valorizar o que Boyer denomina de bordas, aí incluídos o campo, o mar e as montanhas, estas apresentadas como pitorescas. A Paisagem constituída a partir deles será encantadora, nas suas colinas e vales. "Os viajantes enternecidos gozavam de cenas bucólicas onde os montes eram apenas um cenário longínquo; eles viviam ao mesmo tempo os amores de Julie e o "retorno a felicidade intra-uterina"' (Boyer, 2003:43). Os cenários pautados pela beleza serena e pela harmonia, ato contínuo, veem na natureza o local da felicidade, fundamentais ao ideário burguês: "A felicidade é uma idéia nova na Europa', proclamava o revolucionário Saint-Just. A Natureza também o era; o sentimento de Natureza se transformou em amor de um campo considerado como paisagem. O nome de Rousseau está ligado à nova mensagem, mas não é único" (Idem, p. 54).

No campo, nos "prazeres pastorais, a Europa culta conhecia as cantigas de vacas que faziam Jean-Jacques Rousseau chorar" (Idem, p.55). A cidade perde prestígio eno século XVIII é vista como a Babilônia pervertida e poluída, perdendo a aura de civilização. "O country não era mais somente o fundamento das rendas fundiárias da pequena nobreza, mas também um espaço de felicidade; [...] a difusão no conjunto da Sociedade foi rápida: sucesso dos 'currais', dos qua- 
dros de Millet, paixão pelo englishgardens, pela decoração com rochas" (Idem). O trem levava ao campo, para longe das cidades tomadas por fábricas movidas a carvão, que cobriam tudo e todos com fuligem negra. Nessa situação, decorrências que transcendem em muito a datação da situação: perpetua-se, no Turismo, um discurso que o demarca como mobilizado pela fuga, em especial da cidade para junto da natureza; uma natureza e uma paisagem que passam a serem vistas pela janela do trem:

"[...] numerosos textos do fim do século 18 e da época romântica tinham um tom que podemos qualificar atualmente de ecológico. Bem mais do que uma nova moda, era uma construção ideológica; começada na segunda metade do século 18 e continuada no século 19, ela terminou no fim do século 20 com o 'campo desejado', mais apreciado por seu valor estético e terapêutico do que por seu interesse produtivo, conotado desde o século 18 - como o local de Virtude, de Liberdade, de realização do Corpo" (Boyer, 2003:54).

Outra generalização decorrente desse momento, no século XX o turismo de massa, segundo Boyer (Idem, p.55), generalizou os turistas como "consumidores de Natureza, devoradores de paisagens". As montanhas merecem outro capítulo nesta construção de imaginário. Os Alpes foram objeto de curiosidade a partir de 1740 e em seguida de interesse científico. A montanha, nesse momento, deixa de "ser "horrível' para tornar-se sublime" (Idem, p.41) levando as preferências turísticas por elas continuasse presentes:

"Que grande mutação! A montanha era como o Oceano, território de pavor: nos mapas, era representada por espaços brancos com dragões e animais terríveis. Nenhum cume - ou quase nenhum - tinha um nome; os desfiladeiros que eram as passagens obrigatórias dos viajantes, eram qualificados de montes (Mont-Cenis, Mont-Genèvre...). Alguns cumes eram chamados de 'Malditos' ou 'Pilatos', o que dá no mesmo! Em seu conjunto, os montes eram chamados de 'terríveis', 'pavarosos', 'horríveis' por viajantes obrigados a atravessá-los para ir para Itália, que não viam neles nada a admirar e compadeciam-se dos 'cretinos' ou 'papudos' dos Alpes” (Boyer, 2003:41).

Quanto ao mar, Florence Deprest (1997) retoma Corbin para explicar que a ideia de praia também é inventada - pois surgiria algo que não existia - nos anos 1750 , cabendo esta tarefa aos turistas. Antes disto, a praia estaria relegada às margens do território social. A exemplo do que aconteceu com a montanha, cria-se em simultâneo uma relação de lazer e uma relação estéticas com estes espaços.

Barthes, ao analisar o mito na atualidade, atualiza a questão, utilizando para tal os GuideBleu, guias de viagem que são editados a partir de 1918 por James e FindlayMuirhead, antes editores da versão inglesa do Baedeker, que circulava desde o século anterior. Estes guias centravam-se na arte e arquitetura, descrevendo-as em detalhes, para conduzir o desfrute e o prazer estético de seus leitores, nas suas viagens. Para Barthes (1987:72):

"O Guidebleu só reconhece como paisagem o pitoresco. É pitoresco tudo que é acidentado. Encontramos aqui a promoção burguesa da montanha, o velho mito alpestre (data do século XIX) que o Guide associava com razão à moral helvética-protestante e que sempre funcionou como um mito bastardo do de naturalismo e de puritanismo (regeneração pelo ar puro, idéias morais perante os ricos, ascensão como civismo etc.). Entre os espetáculos promovidos pelo Guidebleu à existência estética, raramente se encontra a planície (salvo somente quando se pode dizer que é fértil), nunca o planalto. Só a montanha, a garganta, o desfiladeiro e a torrente podem ascender ao panteão da viagem, sem dúvida na medida em que parecem sustentar uma moral do esforço e da solidão."

Barthes, portanto, avança na análise do pitoresco incorporado pelo turismo, mesmo sem ser um teórico da ciência das viagens. Na sua análise, o pitoresco assim construído valorizaria o que ele chama de marcha moralizante, associada à ética do trabalho. Para tal, mesmo o túnel, segundo Barthes (1987, p. 72), torna-se signo da montanha, ainda que nele não seja possível vê-la, pois "é um valor fiduciário suficientemente forte [...]". O mesmo se daria com a arte e arquitetura destaca no Guide, que só valorizaria monumentos religiosos, "pois de um ponto de vista burguês é quase impossível imaginar uma história da arte que não seja cristã e católica [...].O cristianismo é o primeiro fornecedor do turismo e só se viaja para visitar igrejas" (Barthes, 1987:73).

Ao dizer que o Guide não estimularia no viajante aos questionamentos de "atravessar uma paisagem real, e viva" (Idem), inclusive no seu grifo, Barthes também encaminha como o desa- 
parecimento da natureza, no que se refere à paisagem, foi alimentados pelos guias de viagem, na sua condução do olhar do turista. O desaparecimento da natureza no conceito de paisagem, também está presente nos dicionários mais contemporâneos, de consulta online, que não mais a apresentam associada à beleza natural. Segundo dicionário consultado, pintoresco é "adj. [Paisaje,escena,tipo,etc.] 1 que resulta característico y típico de un lugar: elhotel da a una plazamuypintoresca. 2Curioso, atractivo,expresivo: iqué ocurrencia tan pintoresca! 3 Estrafalario, chocante: lleva una ropa un tanto pintoresca"3. Neste mesmo dicionário online consultado para o termo pintoresco, junto ao verbete havia links remetendo ao turismo.

Excluída a natureza, o pitoresco seria redimensionado, quando as cidades passam a ser buscadas por turistas, para vivências culturais diferenciadas. A mudança dos destinos, daquele junto à natureza, para outros, urbanos, estaria associadas ao envelhecimento da população e ao avanço do consumo cultural para além das elites cultas, mas também a esta natureza que desaparece ou recua, no conceito de paisagem. Uma investigação mais acurada, talvez conduza a conclusão que o pitoresco urbano esteja associado aos jardins e aos ajardinamentos, mas também à qualidade visual exigida dos novos espaços urbanos usufruídos pelos turistas, por exemplo, nos centros históricos restaurados e/ou revitalizados (Gastal, 2006).

Mais recentemente, quando a cidade que se coloca ao olhar do viajante como opção de destino turístico, o espaço lúdico para receber visitantes deixa de se centrar na natureza até por sua menor presença no espaço urbano -, o que seria causa ou consequência, como se preferir, de outras soluções urbanas, de grande impacto, na criação praças pós-modernas nos espaços de convivência como o lobby de hotéis, ou corredores de shoppings de centers, onde a natureza será recuperada nos ajardinamentos, mas também por propostas eletrônicas. A mais surpreendente talvez seja uma grande tela - um imenso frontline -, interligando um complexo de lojas e restaurantes, em Pequim. $\mathrm{Na}$ tela com de 200 metros de extensão, a 50 metros de altura, nadam peixes e sereias. Aos espectadores, a sensação é a de estar no fundo do mar, integrado ao mundo aquático, observando o suave nadar de outros seres marinhos. A mesma tela em outros momentos simula um céu estrelado, onde cometas percorrem a Via Láctea. Beleza pura, levando a uma sensação de grande de bem-estar, complementada por música suave. Tecnologia, publicidade, design e arte somados, para proporcionar uma experiência sensorial inesquecível, em substituição a presença de uma natureza de fato.

\section{Referências}

Barthes, Roland.

1987 Mitologia. São Paulo: Difel.

Barthes. Roland.

1987b A aventura semiológica. Lisboa: Edições 70.

Berque, A.

1998 "Paisagem-marca e paisagem-matriz: Elementos da problemática para uma geografia cultural". In: Correa, R. et al. Paisagem, tempo e cultura. Rio de Janeiro: UERJ.

Boyer, Marc.

2003 História do turismo de massa. Bauru: EDUSC.

Castrogiovanni, AntonioCarlos.

2001 "Por que a geografia do Turismo?". In Gastal, S. (org). Turismo: 9 propostas para um saber-fazer. Porto Alegre: EDIPUC.

Castrogiovanni, Antonio Carlos.

2009 "O lugar da geografia no entre-lugardo espaço turístico: Uma viagem complexa que ainda continua..." Rosa dos Ventos 1(0).

Clark, K.

S/d. A paisagem na arte. Lisboa: Ulisseia.

Cosgrove. D.

1999 "Geografia Cultural do Milênio". In. Rosendahl, Z. et al (org.). Manifestações da cultura no espaço. Rio de Janeiro: Ed. UERJ.

Costa, L.C.N.

2011 "Turismo e paisagem cultural: para pensar o transfronteiriço”. Dissertação. Mestrado em Turismo, Universidade de Caxias do Sul. Caxias do Sul-RS.

Deprest, F.

1997 Inquérito sobre o turismo de massa. Lisboa: Instituto Piaget.

Ferreira, A. Buarque.

S/d. Dicionário da lingua portuguesa. Rio de Janeiro: Nova Fronteira.

Gastal, Susana.

2006 Alegorias Urbanas, o passado como subterfúgio. Campinas: Papirus.

Gastal, Susana.

2005 Turismo, imagem e imaginários. São Paulo: Aleph.

Harvey, David.

1992 A condição pós-moderna. São Paulo: Loyola. Hauser, Arnold

1969. História Social de la literatura e el arte. Madrid: Guadarrama. 
Itau Cultural.

S.d. Enciclopédia Itau Cultural. São Paulo, s.d. Disponível em http://www.itaucultural. org.br/aplicexternas/enciclopedia_ic/index. cfm?fuseaction=termos_texto\&cd_verbete $=3655$, acessado em 20 de maio de 2013 .

Jameson, Fredric.

1996 Pós-modernidade: A lógica do capitalismo tardio. São Paulo: Ática.

Jameson, Fredric.

2001 A cultura do dinheiro. Petrópolis: Vozes.

Jameson, Fredric.

1992 Espaço e imagem: teorias do pós-moderno e outros ensaios. Rio de Janeiro: Editora UFRJ.

LuchiarI, Maria Tereza D.P.

S.d. Urbanização turística um novo nexo entre o lugar e o mundo. Asociación Canaria de Antropología. Prepublicación de Guize, n.4. Disponível emhttp://www.antropologiasocial. org/contenidos/publicaciones/otautores/fortcon.pdf, acesso em maio de 2013.

Read, Herbert

1989 Dicionário das Artes e dos Artistas. Lisboa: Edições 70.

Serrano, Célia M.T.

1997 "Uma introdução à discussão sobre Turismo, Cultura e Ambiente". In.: Serrano, Célia M.T. \&Bruhns, Heloisa T. (org). Viagem à natureza: Turismo, Cultura e Ambiente. Campinas, SP: Papirus,

\section{Notas}

1 Os ecologistas utilizam outras datações, mais antigas, para caracterizar a emergência da consciência ambiental. Optei pela década de 1960, por ser quando ele se expande para a sociedade de uma forma mais ampla.

2 Acessado em http://www.cultura.gov.br/site/?p=5293, em abril de 2010 .

3 Diccionario de la lengua española (C) 2005 Espasa-Calpe S.A., Madrid. Disponível em http://www.wordreference. com/definicion/pintoresco, acesso em março 2009. 